\title{
The Study of Professional Stressor Factors in Nursing and Midwifery Community
}

\author{
Esmat Bandani ${ }^{1}$, Mohammad Ghasemi ${ }^{2}$, Hakimeh Shahryari ${ }^{1}$ \\ ${ }^{1}$ MSc student of Governmental management, Azad University of Zabol, Zabol, IR.Iran \\ ${ }^{2}$ Assistant Professor, Department of management, University of Sistanvbalouchitan, Zahedan, Ir. Iran
}

\begin{abstract}
Background and Aim: Working and employment is chief portion of human social life that can create stress in individual and in turn they will cause dissatisfaction, leaving profession and providing incorrect services to clients. Because of the importance of nursing and midwifery profession this study was carried out to determine profession stressor factors in nursing and midwifery community in Zabol city. Materials and Methods: This descriptive study was to rank professional stressor factors. The Subjects were all nurses and midwives of Zabol Medical University hospitals. A questionnaire was used to collect the data and in order to analyze them we used t-test. Results: The results of this study showed that among professional stressor factors, economic factor had the first rank of stressor factors with $91.5 \%$ mean score. And among aspects of stressor factors, low incomes (with $90.67 \%$ of mean stress score), work difficult conditions (with $88 \%$ of mean stress score) and inadequate personnel (with $87.67 \%$ of mean stress score) gained other levels of stress factors in the study subjects respectively. Conclusion: According to the findings of this study, it is important for managers of hospitals to notice nursing and midwives low income and the difficult conditions of their profession. In this way they can reduce stressor factors among them and in turn it will cause satisfaction and increase in quality of patients cares that finally bring us community health promotion.
\end{abstract}

Keywords: Stressor factors; Nursing; Midwifery; Job

\section{Introduction}

Psychological pressures are the most common and detrimental effective forces in today's societies. Although the industrialized world and its increasing developments have led to collective welfare of people in some respects, they have increased their mental pressures. People's worries about work, social and economic problems, organizations' expectations of employees, advances in technologies, administrative problems, and employees' expectations all cause people deal with pressures, emotions, worries, fears and hopes from dawn to dusk. These are sometimes within the physical, psychological, and emotional capacity of the individual and sometimes are not. The later ones are known as stress(1)Job stress can be defined as physical and emotional responses that are created when personal needs are not proportionate to abilities, talents or the expectations. Therefore, the study of job stress must address the harmony between the environment and the individual (2).

Pressure sources lead to different reactions in different people. Some people can deal with these factors better than others and can cope with the challenging environment, while many people, due to their personality traits, are prone to stress. This means that, in stressful situations, they will not be able to deal with stress factors and will get in trouble. Some of these characteristics include age, gender, health status, exercise patterns and even diet that lead to different reactions in stressful situations (3).Working in an organization and how one deals with individual autonomy and freedom and identifies and evaluates his/her position can be considered a source of stress. This stress is created mainly by unfair policies, job inequality, inflexible rules, repetitive relocations, unrealistic job description, lack of improvements, line and staff conflicts, lack of feedback, incomplete information or absence of information, undue and irritating control, unfair assessments, and misrepresentation (5). Handling jobrelated matters constitute a major part of people's everyday activities. Each job has a similar number of sources of stress. These sources of stress disturb the individual's peace of mind as long as the individual is engaged with the activity. The main job-related sources of stress are as follows: Job motivation is always one of the fundamental issues in the job organization, and managers are constantly searching for solutions to increase the employees' motivation to the expected level. The findings of a study by P Suresh et al. (2002) on the job stressors and their stress levels in hospitals of Ireland showed that the most severe stressor in nurses was dissatisfaction with benefits $(72.5 \%)$, followed by high workload $(61.3 \%)$, weekend shifts $(25.1 \%)$, lack of acceptance of jobs in society $(51.2 \%)$, sleep disorders $(50.7 \%)$, while new equipment at the workplace and lack of the knowledge how to use them (20.4\%) were found to be the least severe stressors (6). Considering the importance of workplace and occupational status in nursing and midwifery professions in societies, this study aimed to determine level of professional stressor factors in nursing and midwifery. Findings can help solve their occupational and professional problems and increase their satisfaction and ultimately improve their health levels.

\section{Methods and Materials}

This was a descriptive survey study that aimed at investigating the effects of job stressors on all nursing and midwifery staff of the Faculty of Medical Sciences of Zabol. The study population included all nursing staff (nurses, auxiliary nurses, anesthesia technicians, and operating room technicians) and midwifery staff. Due to the limited size of the study population, all members were interviewed. Validity of the questionnaire was confirmed 


\section{International Journal of Science and Research (IJSR) \\ ISSN (Online): 2319-7064}

Index Copernicus Value (2013): 6.14 | Impact Factor (2015): 6.391

by experts. Reliability of the questionnaire was confirmed through a test-retest following a pilot study using Pearson correlation coefficient $(\mathrm{P}<0.05$ and $\mathrm{r}=0.82)$. The questionnaire was then made available to all members of the study population $(n=110)$. The first part of the questionnaire was about demographic characteristics including age, gender, work experience, education, place of work, marital status, and employment status. The second part of was related to professional stressors in five categories, including physical factors (9 items), administrative factors (9 items), psychological and physical factors (4 items), socio-cultural factors (5 items), and economic factors ( 3 items) (a total of 30 items). The stressfulness level of the factors was scored by the nurses and midwives based on a Likert scale from very high to very low. The final part of the questionnaire included open questions on other stressors and their stressfulness level. T-test and statistical tests at significant level of $\mathrm{P} \leq 0.05$ were used for data analysis. Frequency tables and tendency and dispersion of center were used. A bar graph was used to display the results of data analysis.

\section{Results}

A total of 92 questionnaires were completed and returned. Most subjects were 25-35 years old (mean age of 31.76), female, with work experience of 5-20 years, held a bachelor's degree, were married and in the nursing group (auxiliary nurses, anesthesia technicians, and operating room technicians).Among the physical stressors, unsuitable commuting conditions (stress score of 76.83\%) and lack of resting facilities (stress score of 76\%) ranked first and second, respectively. The least stress score corresponded to lack of equipment (stress score of $70.67 \%$ ) (Table 1). It should be noted that the physical stress had 9 dimensions, each of which was scored based on a Likert scale from 1 to 6 , meaning that the minimum and maximum scores were 9 and 54, respectively.

Among the physical-mental stressors, difficult working conditions (stress score of $88 \%$ ) and work-related fatigue (stress score of $88 \%$ ) ranked first and second, respectively (Table 2).

Table 1: Physical stressors ranking

\begin{tabular}{|l|c|c|c|c|}
\hline \multicolumn{1}{|c|}{ Physical stressor } & Mean score & Stressfulness (\%) & Rank in group & Rank in total \\
\hline Noise pollution in the workplace & 4.48 & 74.67 & 3 & 20 \\
\hline Air pollution in the workplace & 4.39 & 73.17 & 6 & 23 \\
\hline Improper temperature & 4.38 & 73 & 7 & 24 \\
\hline Workspace constraints & 4.47 & 74.5 & 4 & 21 \\
\hline Lack of resting facilities & 4.65 & 76 & 2 & 18 \\
\hline Lack of working equipment & 4.24 & 70.67 & 9 & 24 \\
\hline Unsuitable working equipment & 4.25 & 70.83 & 8 & 25 \\
\hline Unsuitable health conditions & 4.43 & 73.83 & 5 & 22 \\
\hline Unsuitable commuting conditions & 4.61 & 76.83 & 1 & 17 \\
\hline
\end{tabular}

Table 2: Physical-mental stressors ranking

\begin{tabular}{|l|c|c|c|c|}
\hline \multicolumn{1}{|c|}{ Physical stressor } & Mean score & Stressfulness (\%) & Rank in group & Rank in total \\
\hline Job-related fatigue & 5.08 & 84.67 & 2 & 11 \\
\hline Job-related physical ailments & 4.65 & 77.5 & 4 & 16 \\
\hline Difficult working conditions & 5.28 & 88 & 1 & 3 \\
\hline Job-related psychological disorders & 4.98 & 83 & 3 & 12 \\
\hline
\end{tabular}

Regarding the relationship between stressors and employment status of the subjects, contract employees reported higher stress levels on all the stressors, whereas permanent employees reported higher stress levels on administrative stressors than other groups (except for contract employees).

\section{Discussion}

Most researchers consider stress as a factor that deteriorates energy. The causes of this phenomenon should be analyzed in a way that it can be used in prevention as well. In this study, inappropriate commuting conditions and lack of resting facilities were identified as the most important physical stressors. The lack of adequate staff and high number of patients were the most important administrative stressors. Attar-Parsaei and F Moradipanah (2009) studied the stressor factors in emergency department in Tabriz and reported that organizational management-related stressors with average intensity of $75.2 \%$ were the most important stress factors, followed by physical environment factors, interpersonal factors, and care factors (7).
The results of a study by Navidian et al. (2005) in Zahedan titled "study of occupational stressors and their relationship with nurses' general health" showed that the most important stressors were care-related (2.54) and management-related (2.28). Intensity of stressors in the nurses was greater than auxiliary nurses (8). Among sociocultural stressors, responsibility towards patients ranked first, followed by lack of suitable standing in the society; thus, one of the important issues in the nursing profession is responsibility towards the patients and their families, which must be addressed by nursing managers (9). In this study, among the economic stressors, low income level was the most important, followed by non-payment of salaries in time. Findings of a study titled "stressors of nurses in the emergency department of Ardabil's hospitals" by E Habibi (2014) showed that shortage and unavailability of equipment and facilities (with a frequency of $67.34 \%$ ), seeing patients (with a frequency of $5 \%$ ), interference of patients' relatives in providing nursing care (with a frequency of $53.06 \%$ ), nursing staff shortages, unavailability of doctors in emergencies, not involving nurses in department's decision-makings, and working in consecutive shifts (with a frequency of 


\section{International Journal of Science and Research (IJSR) \\ ISSN (Online): 2319-7064}

Index Copernicus Value (2013): 6.14 | Impact Factor (2015): 6.391

$42.14 \%$ ) were the most important stressors in the nurses working in the emergency department. Based on these findings, the main cause of stress is shortage and unavailability of required facilities (10).

\section{Conclusion}

Findings suggest that economic factors are the most important stressors, followed by physical-mental, administrative, and socio-cultural factors. Therefore, more attention must be paid to economic factors and low income levels. Resolving such issues reduces stress levels and increases satisfaction, leading to an increased quality of care.

\section{References}

[1] Garrosa, Eva, et al. "The relationship between sociodemographic variables, job stressors, burnout, and hardy personality in nurses: An exploratory study." International Journal of Nursing Studies 45.3 (2008): 418-427.

[2] Payne, Nicola. "Occupational stressors and coping as determinants of burnout in female hospice nurses." Journal of advanced nursing 33.3 (2001): 396-405.

[3] Chang, Esther M., et al. "The relationships among workplace stressors, coping methods, demographic characteristics, and health in Australian nurses." Journal of professional nursing 22.1 (2006): 30-38

[4] Duquette, AndrÉ, et al. "Factors related to nursing burnout a review of empirical knowledge." Issues in Mental Health Nursing 15.4 (1994): 337-358.

[5] MONTES-BERGES, B., and J-M. AUGUSTO. "Exploring the relationship between perceived emotional intelligence, coping, social support and mental health in nursing students." Journal of Psychiatric and Mental Health Nursing14.2 (2007): 163-171.

[6] Suresh, Patricia, Anne Matthews, and Imelda Coyne. "Stress and stressors in the clinical environment: a comparative study of fourth-year student nurses and newly qualified general nurses in Ireland." Journal of clinical nursing 22.5-6 (2013): 770-779.

[7] Moradipanah, F., E. Mohammadi, and A. Z. Mohammadil. "Effect of music on anxiety, stress, and depression levels in patients undergoing coronary angiography." (2009).

[8] Navidian, Ali, Gholam Reza Masoudi, and Soudabeh Mousavi. "Work-related Stress and the General Health of Nursing Staffs in Zahedans' Hospitals Emergency Wards (2004)." Journal of Kermanshah University of Medical Sciences (J Kermanshah Univ Med Sci) 9.3 (2005).

[9] Gelsema TI. A longitudinal study of job stress in the nursing profession: Causes and Consequences. J Nurs Manage. 2006; 14 (4): 289-99.

[10]Habibi, Ehsanollah, et al. "Effects of work-related stress on work ability index among refinery workers." Journal of education and health promotion3.1 (2014): 18 